\title{
ADHERENCE EFFECTS OF A CARDIAC REHABILITATION PROGRAM IN PATIENTS AFTER MYOCARDIAL INFARCTION
}

Ugne Motiejuniene ${ }^{1}$, Erika Liovaite ${ }^{1}$, Alfredas Rudys ${ }^{1}$, Jurate Guogiene ${ }^{1}$, Asta Grigaliuniene ${ }^{1}$, Juozas Jankauskas $^{1}$, Ausra Kukulskiene ${ }^{1}$, Romualda Leisiene ${ }^{1}$, Nelli Bickauskaite ${ }^{1}$, Kristina Misiukiene ${ }^{1}$, Saule Meskauskiene $^{1}$, Gintare Narmontaite ${ }^{1}$, Egle Paleviciute ${ }^{1}$, Barbara Semetiene ${ }^{1}$, Jurate Poderiene ${ }^{1}$ ${ }^{1}$ Vilnius University Hospital Santaros clinics (VULSK) Rehabilitation, Physical and Sports medicine centre, Vilnius, Lithuania

\section{Introduction}

Cardiac rehabilitation program (CRP) improves exercise capacity (EC), quality of life (QOL), psychological well-being, however, participation rates are low. Little research is done on adherence effects of CRP in patients after myocardial infarction (MI) in Lithuania.

\section{Purpose}

To evaluate the adherence to CRP on clinical stability, EC, QOL following 6 months after MI.

\section{Methods}

A prospective study was performed in 46 patients after acute Ml. 54.5\% ( $\mathrm{N}=12)$ patients were with STEMI, 45.5\% ( $\mathrm{N}=10)$ - with NSTEMI. Average age - $59 \pm 7$ years. Screening period consisted of an inpatient rehabilitation for 2 weeks and outpatient for 27 weeks. Hemodynamic parameters, blood panels, heart ultrasound (left ventricle ejection fraction - LV EF), EC (bicycle stress test, 6 minute walk test), daily walking distances, health questionnaires (EuroQoL Five Dimensions Three Levels, International Physical Activity Questionnaire) and cardiovascular risk factors were examined during the time of the study. Only 22 patients completed the study $(47.8 \%)$.

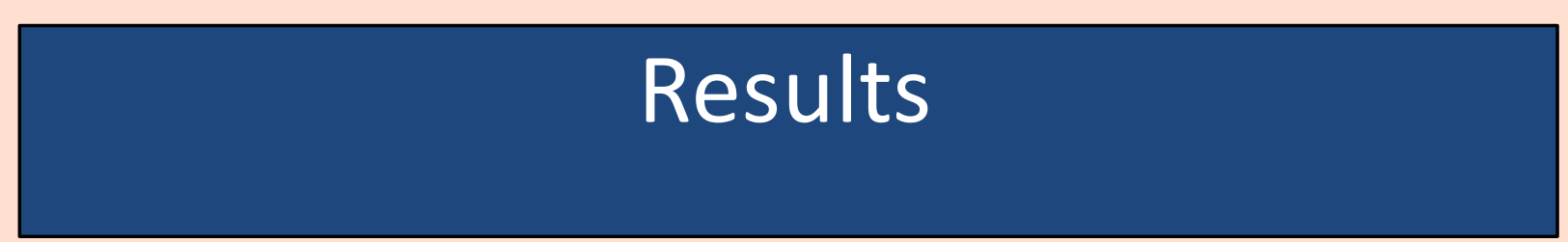

$\mathrm{BP}, \mathrm{BMI}$, waist circumference remained unchanged. Heart rate decreased from $68 \pm 9.1 \mathrm{bmp}$ to $65 \pm 5.5$ bmp $(P<0.21)$, BNP - from $200.9 \pm 198.4 \mathrm{ng} / \mathrm{l}$ to

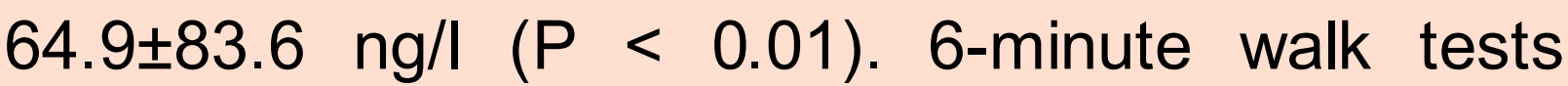
distance increased from $400.6 \pm 88.2 \mathrm{~m}$ to $510 \pm 61.1$ m $(P<0.003)$; bicycle stress test results - from 111.6 $\pm 21.3 \mathrm{~W}$ to $133.3 \pm 20.4 \mathrm{~W}(\mathrm{P}<0.02)$. EF increased from $45.2 \pm 8.6 \%$ to $49.6 \pm 4.8 \%(P<0.04)$. Average walking distance increased from $4.1 \pm 1.4$ $\mathrm{km} / \mathrm{d}$ to $4.9 \pm 1.5 \mathrm{~km} / \mathrm{d}(P<0.09)$, average steps count - from $5032 \pm 2050$ to $6002 \pm 1993, P<0.07$ ). Patients spent more time walking (increased from $2.2 \pm 1.1 \mathrm{~h} / \mathrm{d}$ to $2.8 \pm 1.3 \mathrm{~h} / \mathrm{d}, \mathrm{P}<0.1)$. Subjective satisfaction of health increased $20 \%(P<0.02)$. At the beginning $31.8 \%(\mathrm{~N}=7)$ smoked, after 6 months none ceased. LDL decreased from $3.57 \pm 0.74$ $\mathrm{mmol} / \mathrm{l}$ to $2.74 \pm 0.6 \mathrm{mmol} / \mathrm{l}(\mathrm{P}<0.36)$.

\section{Conclusions}

Program adherence was moderate - 47.8\% completed. CRP improved EC, QOL.

\section{6-minute walk test distance, $m$ $p<0,003$}
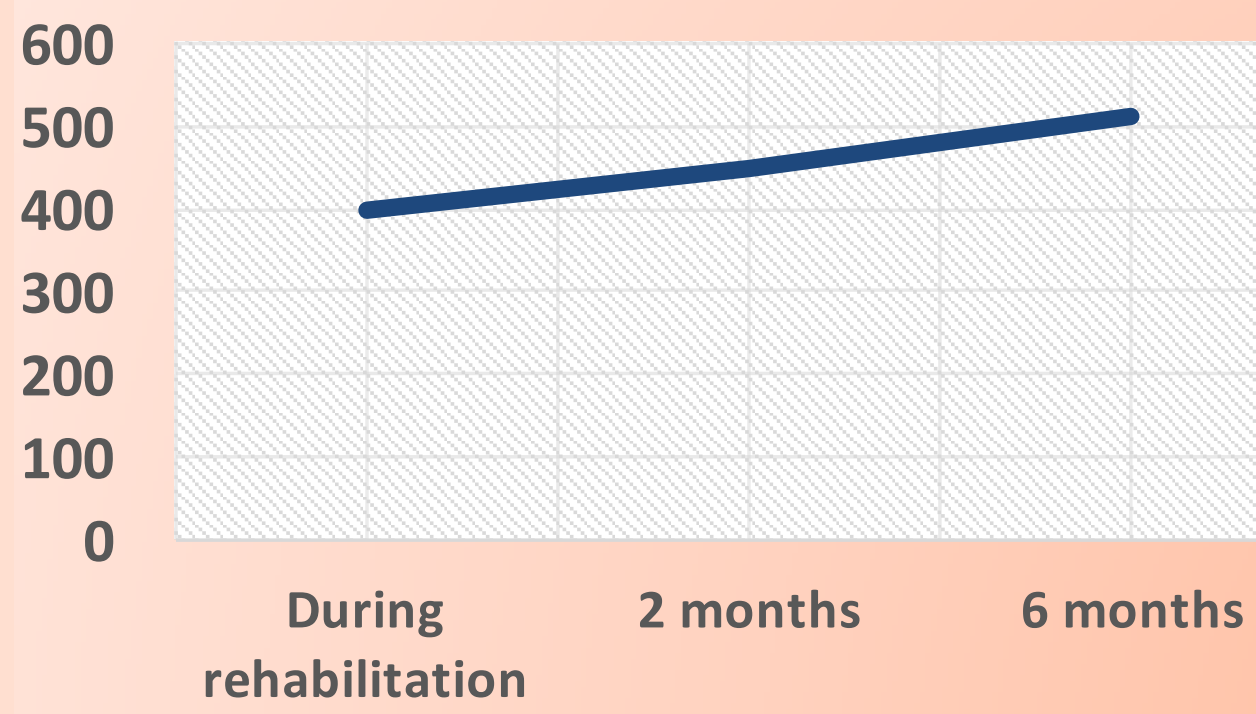